\title{
Liquid Mosquito Repellents - Keep Them Away from Toddlers
}

\author{
Vijay Kumar $^{1} \cdot$ Jhuma Sankar ${ }^{1}$ (D)
}

Received: 19 November 2019 / Accepted: 19 November 2019 / Published online: 4 December 2019

(C) Dr. K C Chaudhuri Foundation 2019

Preschool children are at high risk of unintentional toxin exposure as they are inquisitive, do not recognize harm and commonly tend to mouth objects. Ingestion of liquid mosquito repellents are increasingly being reported from urban households from India [1, 2]. To combat the menace of vector borne diseases like dengue and malaria these compounds are increasingly being used. Rural and suburban families are vulnerable as they tend to store these liquids unattended over the floor or within the reach of toddlers in single use plastic water containers. Majority of the exposure occurs during summer months possibly thirst being a contributor.

The active compound in these liquids is pyretheroid which is only $1 \%$ of the solution, and the solvent used is a hydrocarbon, usually kerosene (which is $\sim 97 \%$ of the solution). Pyrethroids are generally considered safe for human use owing to their poor dermal absorption, rapid metabolism and little tissue accumulation. There are few cases of human toxicity reported with pyrethroids [3, 4]. Pyrethroids act on voltage-gated sodium channels and GABA-gated chloride channels leading to CNS symptoms such as headache, seizures, drowsiness, dizziness and occasionally respiratory failure. Lung injury in liquid mosquito repellent ingestion is most often attributed to aspiration of the solvent hydrocarbon and has been commonly reported [1, 2]. Hydrocarbon aspiration results in chemical pneumonitis leading to need for respiratory support, hospitalization and rarely mortality due to severe acute respiratory distress syndrome. In this issue of Indian Journal of Pediatrics, Reddy et al. report the epidemiology, clinical profile, management and outcomes of 23 children admitted to their emergency over a period of $5 \mathrm{y}$ [5].

Toddlers from urban educated families, during summer months were predominantly affected. All symptomatic children had respiratory manifestations akin to aspiration

Jhuma Sankar

jhumaji@gmail.com

1 Department of Pediatrics, All India Institute of Medical Sciences, New Delhi 110029, India pneumonitis of hydrocarbon ingestion [6]. However, a small proportion also had seizures and altered sensorium which could be attributed to the pyrethroid component of the liquid mosquito repellent. Management of pyrethroid poisoning is mostly supportive. The authors therefore rightly emphasize that management should be on the lines of hydrocarbon ingestion - to avoid induced vomiting or gastric lavage, timely skin decontamination, provide supportive care and respiratory support if needed [5]. Unfortunately, in this series more than half the children had undergone gastric lavage or induced vomiting in the pre-referral health facility before presenting to the emergency. Increasing awareness among physicians practicing in remote corners of the urban areas could significantly limit this harm. Like any other poisoning, prevention is the key. This could be achieved by creating awareness in urban families, appropriate storage and use of these repellents away from the reach of children and implementing regulations to design child safe containers.

\section{References}

1. Prasad R, Singh A, Mishra OP. An accidental ingestion of mosquito repellent liquid vapouriser. Indian J Pediatr. 2015;82:1179-80.

2. Chandelia S, Dubey NK. Mosquito repellent vaporizer poisoning-is the culprit transfluthrin or kerosene? Indian Pediatr. 2014;51:319.

3. Bradberry SM, Cage SA, Proudfoot AT, Vale JA. Poisoning due to pyrethroids. Toxicol Rev. 2005;24:93-106.

4. Ray DE, Ray D, Forshaw PJ. Pyrethroid insecticides: poisoning syndromes, synergies, and therapy. J Toxicol Clin Toxicol. 2000;38:95101.

5. Reddy MV, Ganesan SL, Narayanan K, et al. Liquid mosquito repellent ingestion in children. Indian J Pediatr. 2019. https://doi.org/10. 1007/s12098-019-03088-y.

6. Jayashree M, Singhi S, Gupta A. Predictors of outcome in children with hydrocarbon poisoning receiving intensive care. Indian Pediatr. 2006;43:715-9.

Publisher's Note Springer Nature remains neutral with regard to jurisdictional claims in published maps and institutional affiliations. 